\title{
AZFa candidate gene UTY and its $X$ homologue UTX are expressed in human germ cells
}

\author{
Peter H Vogt' ${ }^{\text {, Jutta Zimmer }}{ }^{\text {, Ul Uike Bender }}{ }^{1}$ and Thomas Strowitzki² \\ 1Division of Reproduction Genetics, Department of Gynaecol. Endocrinology \& Infertility Disorders, Women Hospital, University of Heidelberg, Germany \\ 2Department of Gynaecol. Endocrinology \& Infertility Disorders, Women Hospital, University of Heidelberg, Germany
}

Correspondence should be addressed to P H Vogt: peter.vogt@med.uni-heidelberg.de

\begin{abstract}
The Ubiquitous Transcribed Y (UTY a.k.a. KDM6C) AZFa candidate gene on the human Y chromosome and its paralog on the $\mathrm{X}$ chromosome, UTX (a.k.a. KDM6A), encode a histone lysine demethylase removing chromatin H3K27 methylation marks at genes transcriptional start sites for activation. Both proteins harbour the conserved Jumonji C (JmjC) domain, functional in chromatin metabolism, and an extended N-terminal tetratricopeptide repeat (TPR) block involved in specific protein interactions. Specific antisera for human UTY and UTX proteins were developed to distinguish the expression of both proteins in human germ cells by immunohistochemical experiments on appropriate tissue sections. In the male germ line, UTY was expressed in the fraction of A spermatogonia located at the basal membrane, probably including spermatogonia stem cells. UTX expression was more spread in all spermatogonia and in early spermatids. In female germ line, UTX expression was found in the primordial germ cells of the ovary. UTY was also expressed during fetal male germ cell development, whereas UTX expression was visible only at distinct gestation weeks. Based on these results and the conserved neighboured location of UTY and DDX3Y in Yq11 found in mammals of distinct lineages, we conclude that $U T Y$, such as $D D X 3 Y$, is part of the Azoospermia factor a (AZFa) locus functioning in human spermatogonia to support the balance of their proliferation-differentiation rate before meiosis. Comparable UTY and DDX3Y expression was also found in gonadoblastoma and dysgerminoma cells found in germ cell nests of the dysgenetic gonads of individuals with disorders of sexual development and a Y chromosome in karyotype (DSD-XY). This confirms that AZFa overlaps with GBY, the Gonadoblastoma susceptibility Y locus, and includes the UTY gene.
\end{abstract}

\section{Lay Summary}

AZFa Y genes are involved in human male germ cells development and support gonadoblastoma (germ cell tumour precursor cells) in the aberrant germ cells of the gonads of females with genetic disorders of sexual development. The AZFa UTY gene on the male $Y$ chromosome is equivalent to UTX on the female $X$ chromosome. These genes are involved in removing gene regulators to enable activation of other genes (i.e. removal of histone methylation known as epigenetic modifications). We wanted to learn the function of UTY and UTX in developing sperm and eggs in human tissues and developed specific antibodies to detect both proteins made by these genes. Both UTY and UTX proteins were detected in adult and fetal sperm precursor cells (spermatogonia). UTX was detected in egg precursor cells (primordial germ cells). UTY was detected in gonadoblastoma and dysgerminoma tumour cells (germ cell tumours originating from genetic disorders of sexual development due to having a Y chromosome). Based on our study, we conclude that UTY is not only part of AZFa, but also of GBY the overlapping gonadoblastoma susceptibility $Y$ region.

Key Words: • UTY $(\mathrm{KDM6C})$ - UTX (KDM6A) • human spermatogonia function • AZFa locus • GBY tumour susceptibility locus

Reproduction and Fertility (2021) 2 151-160

https://raf.bioscientifica.com

https://doi.org/10.1530/RAF-20-0049 (c) 2021 The authors Published by Bioscientifica Ltd

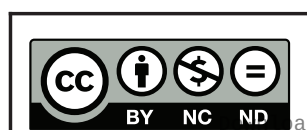

This work is licensed under a Creative Commons Attribution-NonCommercial-NoDerivatives 4.0 International License. ded from Bioscientifica.com at 04/25/2023 11:52:58PM 


\section{Introduction}

The human UTY (Ubiquitous Transcribed Y; a.k.a KDM6C) and UTX (Ubiquitous Transcribed X; a.k.a. KDM6A) genes (OMIM acc.: UTY: 400009; UTX: 300128) are functional members of the histone lysine demethylase 6 (KDM6) gene family (UTY: KDM6C; UTX: KDM6A) capable of removing histone 3 specific lysine (K) 27 methyl marks, H3K27me2/3, from chromatin at genes transcriptional start sites (TSS); thereby activating them for expression (Walport et al. 2014, Gazova et al. 2019). KDM6 proteins are characterised by the highly conserved Jumonji C (JmjC) domain functional in chromatin metabolism (Accari \& Fisher 2015). Chromatin domains marked with $\mathrm{H} 3 \mathrm{~K} 27 \mathrm{me} 2 / 3$ sites are repressed by binding of the methyltransferase Polycomb Repressor Complex 2 (PRC2). PRC2 binding is enriched in embryonic stem cells at promoters of genesencodingkey developmental transcription factors and components of critical signalling pathways to promote cellular differentiation (Pasini et al. 2008). Methylation of H3K27 sites is therefore considered to be an epigenetic mark for maintaining embryonic stem (ES) cell pluripotency. Their plasticity is controlled by distinct H3K27me2/3 demethylases encoded by the KDM6 genes, also expressed during early embryonic development (Welstead et al. 2012). Maintenance of dynamic steadystate levels of dimethylation and trimethylation of histone 3 lysine 27 (H3K27me2/3) in embryonic stem cells indicates thus a functional balance of expression of PRC2 and KDM6 proteins in these cells (Lee et al. 2007, Pasini et al. 2008).

Consequently, some developmental disorders are associated with dysfunction of this essential network control mechanism (Faundes et al. 2018). In human, microdeletions and point mutations of UTX cause Kabuki syndrome characterised by unique facial appearance, growth retardation, skeletal abnormalities and intellectual disability (Banka et al. 2015). Variable UTY and UTX expression profiles are found in distinct cancer cells suggesting some allelic compensation in the case of UTY for UTX deletions present in distinct groups of medulloblastoma (Robinson et al. 2012) as well as other human cancer cell lines (van Haaften et al. 2009).

UTY deletions seem not to be associated with somatic pathologies, although the genes transcripts and proteins were found to be expressed in multiple human tissues and leukocytes (Lahn \& Page 1997, www.uniprot.org/uniprot/ O14607). It has, therefore, been argued that UTY proteins are probably only required for some male cell-specific functions such as expressing a specific $\mathrm{H}-\mathrm{Y}$ antigen (Warren et al. 2000) being restricted to some male-specific organs, such as the prostate (Dutta et al. 2016).

However, UTY deletions may cause complete absence of male germ cells because this $\mathrm{Y}$ gene is part of AZFa, a genomic $Y$ region in the proximal part of the long arm of the human Y chromosome (Yq11.1) conserved in mammals since at least 70 Mya (Vogt et al. 2007). AZFa has a genomic extension of $1.1 \mathrm{Mb}$ and includes a microdeletion found as de novo mutation event in about $9 \%$ of infertile men with a severe testicular pathology including complete germ cell aplasia (Kamp et al. 2001). AZFa is thus part of the Azoospermia Factor (AZF) locus mapped to distinct parts of the long Y arm (Tiepolo \& Zuffardi 1976, Vogt et al. 1996). Recently it has been shown that AZFa might overlap with the Gonadoblastoma $Y$ (GBY) locus in proximal Yq11, including the AZFa candidate genes, USP9Y, $D D X 3 Y$, and $U T Y$, respectively (Vogt et al. 2019). Indeed, protein expression of the AZFa candidate gene DDX3Y in the germ cells of individuals with disorders of their sexual development (DSD) and a Y chromosome in their karyotype (DSD-XY individuals) seems to contribute to the susceptibility function of GBY to induce gonadoblastoma cells in these germ cells.

Since single USP9Y deletions can be inherited (Luddi etal.2009). Therefore, single $D D X 3 Y$ deletions are considered to cause mainly the severe testicular pathology of AZFa deletions (Tyler-Smith \& Krausz 2009). This assumption gained support by the finding that DDX3Y proteins are only expressed in pre-meiotic spermatogonia (Ditton et al. 2004). However, nothing is yet known about the expression of UTY in the human male germ line and single UTY gene deletions in men have not yet been reported.

In the mouse, only Jmjd3 (Kdm6b), of the KDM6 gene family is functionally expressed in spermatogonia (Iwamori et al. 2013). Also, the KDM6 antagonist EZH1, encoding the H3K27 methylation enzyme in the PRC2 complex is mainly expressed in mouse spermatogonia $\mathrm{Mu}$ et al. 2017). It is therefore most likely, that also in human KDM6 genes are functional in the germ line.

In this paper, we wanted to clarify this for the X-Y homologous, UTY and UTX gene pair asking the question (a) in which phase of male germ line UTY and UTX proteins are expressed predominantly; (b) whether UTX proteins are also expressed in female germ cells? Since there are no commercial UTY and UTX specific antisera available, that is, not cross reacting also to the homologous UTX, respectively, UTY proteins, we had to generate reliable UTY and UTX-specific antibodies as a first step. https://raf.bioscientifica.com

https://doi.org/10.1530/RAF-20-0049 (c) 2021 The authors Published by Bioscientifica Ltd 


\section{Materials and methods}

\section{Human tissue sampling and analysis}

All human testis and ovarian tissue sections analysed with distinct antibodies in our immune-histochemical experiments were collected only after written consent was obtained from the patients. Accordingly, the studies were formally approved by the local ethics committees of the University of Copenhagen for the fetal samples (4 specimens collected from gestation week (gw) 16, 25, 33, and 41, respectively, as indicated in the figure legends; and of the University of Heidelberg and of Bonn for the adult samples $(4 \times \mathrm{KOHO} 3$ specimens always used as the control sample for testis sections; $2 \times$ ovarian tissue sections from sample \#1469/99; 4× DSD-46,XY: 2× gonadal tissue sections from GBY88 Swyer patient with Gonadoblastoma nests (see also Vogt et al. 2019) and from $2 \times$ gonadal tissue sections from GBY121 Swyer patient with dysgerminoma. Collection of more than one sample for each experiment from each of the specimen listed above was not possible due to the low number of tissue samples available in the clinic from the fetal germ lines, respectively, from the small aliquots of tissue samples got from each adult patient when suffering from gonadoblastoma or dysgerminoma, respectively. Pathologic assessment of gonadal histology was performed using current terminology (Ulbright \& Young 2014).

\section{Preparation of specific polyclonal UTY and UTX antisera}

The human UTY and UTX proteins are strongly conserved along the complete protein-coding sequence (89\%). Commercially available UTY antisera analysed were found to recognise also the UTX protein (data not published). Since our research questions definitely require specific UTY antibodies marking only UTY proteins in the testicular tissue section, we selected the 'VEKLLSSGAF' peptide of UTY (UTY protein sequence pos: 609-618 aa; accession no.: NP001245178.1; named UTY-1) and the 'NLPQGSLQNKTKLLPSIEF' peptide of the UTX protein (UTX protein sequence pos: 403-421 aa; accession no.: NP001278344; named UTX-1) as putatively specific antigen targets for preparation of specific UTY and UTX antisera in rabbits. They were synthesised by Peptide Speciality Laboratories GmbH (Heidelberg, Germany); conjugated to a carrier protein (maleimide-activated keyhole limpet haemocyanin; KLH; $1 \mathrm{mg}$ peptide/1 mg $\mathrm{KLH}$ ) via C-terminal cysteine residues using the Inject
Activated Immunogen Conjugation Kit (Pierce) and finally subcutaneously injected into New Zealand White rabbits following a standard booster protocol. Specificity and titre of the antisera were analysed by hybridisation to ovalbumin coupled parental peptides spotted at different concentrations onto nitrocellulose membrane stripes (Sartorius, Goettingen, Germany). The UTY-1 antiserum detected only the corresponding UTY-1 peptide; the UTX-1 antiserum only the corresponding UTX-1 peptide. Positively reacting antisera were enriched from the crude blood serum by ammonium sulphate precipitation and purified by affinity chromatography (SulfoLink Coupling Gel Support resin; Pierce). All fractions containing a positive cross-reaction to only their parental peptide were brought to neutral $\mathrm{pH}$ conditions with $1 \mathrm{M}$ Tris buffer (pH 8) and stored in siliconised tubes with 50\% glycerol at $-80^{\circ} \mathrm{C}$.

\section{Preparation of UTY and UTX His-tagged recombinants} expressed in M15 (pREP4) cells

His-tagged UTY- and UTX-recombinants expressed in M15 (pREP4) cells were constructed by cloning a cDNA sequence of the UTX exon 13-17 region including the UTX-1 target peptide in exon 13 and a cDNA sequence of the exon 16-18 region including the UTY-1 target peptide in exon 17 using the KpnI and SalI cloning sites of the pQE80L expression vector (The QIAexpressionist ${ }^{\mathrm{T}}$; Q Qiagen).

Expression of the His-tagged-UTY- and UTXrecombinants in M15 (pREP4) cells was induced with $1 \mathrm{mM} 1 \mathrm{mM}$ IPTG (0, 30 and $60 \mathrm{~min})$ and increasing quantities detected on western blots after incubation with Tetra-His antiserum (Qiagen). Two clones with the highest expression titre (UTX-1K37 and UTY-1 K36) were preserved with $15 \%$ glycerol at $-80^{\circ} \mathrm{C}$. Large quantities of proteins from the selected UTX-1 K37 and UTY-1 K36 recombinants were prepared in $200 \mathrm{ml} \mathrm{LB}$ medium after growing the cells to $\mathrm{OD}_{600} \sim 0.9-1.0$ and 60 min induction with $1 \mathrm{mM}$ $1 \mathrm{mM}$ IPTG. The recombinant UTX and UTY proteins were purified after sonication ( $5 \mathrm{~s}$ bursts with microtip) by HisTag affinity chromatography using an imidazol gradient between 0.1 and $0.25 \mathrm{M}$. Fractions of the pure protein were collected and stored at $-80^{\circ} \mathrm{C}$.

\section{Western blots}

For Western blotting experiments $2 \mu \mathrm{g}$ of the purified recombinant UTX-1K37 and UTY-1K36- proteins were two times loaded in parallel onto a 15\% SDS-PAGE for size fractionation; then, electrophoretically transferred onto

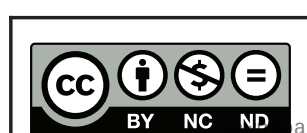

This work is licensed under a Creative Commons Attribution-NonCommercial-NoDerivatives 4.0 International License. International License.
aded from Bioscientifica.com at 04/25/2023 11:52:58PM 
an Immobilon-P membrane (MilliporeEschborn). After pre-incubation of the membranes in blocking solution (5\% skimmed milk powder in $1 \times$ TNT (50 mM Tris, 150 $\mathrm{mM} \mathrm{NaCl}, 5 \mathrm{mM}$ EDTA and 0.05\% Tween 20; pH 7.6)) for $60 \mathrm{~min}$ at room temperature, the two UTX-1K37-UTY-1K36 blot doublets were separated and one stained for UTY with the affinity-purified UTY-1 antiserum, the second stained for UTX with the UTX-1 antiserum (1:150, v/v) overnight at $4^{\circ} \mathrm{C}$. Visualisation of the hybridisation pattern was achieved by incubation with an anti-rabbit IgG-peroxidase conjugate $(1: 20,000, \mathrm{v} / \mathrm{v})$ as secondary antibody (Dianova, Hamburg, Germany) in the same blocking solution for 60 min and using the Western Lightning Chemiluminescence Reagent Plus kit (Perkin Elmer, Langen, Germany) according to the manufacturer's instructions.

\section{Immunohistochemical experiments with UTY and UTX specific antisera UTY-1, UTX-1}

Immunohistochemical experiments with the polyclonal UTY and UTX specific antibodies for analysis of its expression in fetal (only UTY-1) and adult serial paraffin fixed human testis tissue section, respectively, in gonadal tissue sections of distinct DSD-XY individuals (only UTY1) were performed as follows: for all experiments, we used 4-5 $\mu \mathrm{m}$ sections from tissue samples fixed in buffered formaldehyde, or in Bouin's fixative and subsequently embedded in paraffin. They were dewaxed, and then rehydrated in decreasing concentrations of ethanol. Immunohistochemistry staining was carried out with a standard indirect peroxidase method as described by Gueler et al. (2012). In short: antigen retrieval was achieved by incubation of the slides overnight with $0.2 \mathrm{M}$ boric acid, $\mathrm{pH} 7$ at $60^{\circ} \mathrm{C}$. After washing in permeabilisation buffer (0.1 M Tris, 0.1 M NaCl, 0.1\% Triton X-100; pH 7.4), endogenous peroxidase was quenched by incubation in $3 \% \mathrm{v} / \mathrm{v}$ hydrogenperoxide in methanol for $10 \mathrm{~min}$ at room temperature followed by $3 \% \mathrm{v} / \mathrm{v}$ goat serum (NGS) in permeabilisation buffer for $1 \mathrm{~h}$ to block unspecific Ig-binding sites. Sections were incubated overnight at $4^{\circ} \mathrm{C}$ with diluted primary polyclonal UTY-1, UTX-1, DBY-10 (for specific DDX3Y detection) antibodies using the following antisera dilutions: UTX-1 (1:60), UTY-1 (1:60). DBY-10 (1:500). A secondary biotinylated goat-anti-rabbit antibody was applied, followed by incubation with an avidin-biotin complex (Vector Laboratories, Burlingame, CA, USA or Zymed, San Francisco, CA, USA). Finally, slides were stained with DAB (3,3'-diamino-benzidine tetrahydrochloride), counterstained with Mayer's haematoxylin and mounted in Immuno-Mount.

\section{Results}

UTY-1/UTX-1 antisera only mark their parental peptides on Western blots

The specificity of our polyclonal UTY-1 and UTX-1 antisera prepared for detection of only UTY and not UTX proteins, or of only UTX and not UTY proteins, respectively, was controlled by using specific peptide blot tests and peptide specific affinity chromatography (see 'Materials and methods' section). Most crucial, however, would be an analysis of their specificity using western blots containing fractionated protein extracts of recombinant UTY- and UTX-fusion peptides from the same exon region produced after transfection in Escherichia coli and specific IPTG induction (for details see 'Materials and methods' section). Blotting these protein extracts in parallel after gel electrophoresis on nylon membranes, we can demonstrate that the UTY-1 antiserum indeed only detects the recombinant parental UTY-peptide sequence and not the UTX-fusion peptide containing the same exon region. Similar, the UTX-1 antiserum only detects the parental UTX peptide but not the UTY analogue (Fig. 1). We, therefore, provide evidence, that our polyclonal UTY-1 and

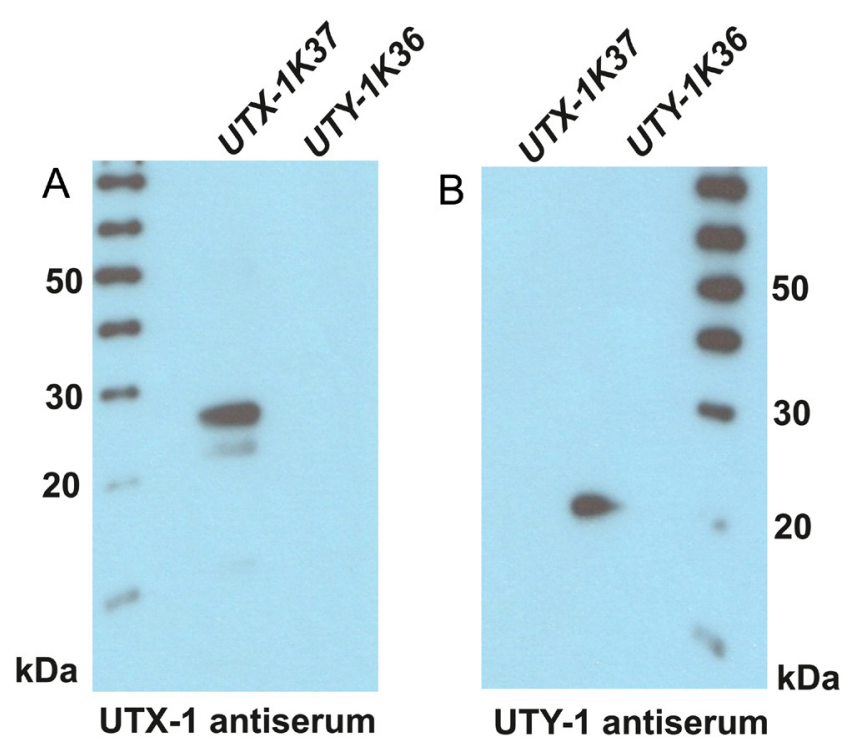

Figure 1 Western blot doublets with protein extracts of UTX1K37 and UTY-1K36 recombinants expressed in M15 (pREP4) cells after IPTG induction (60 min with $1 \mathrm{mM} 1 \mathrm{mM}$ IPTG). (A) First doublet stained for UTX with UTX-1 antiserum display cross-reaction only with the parental UTX-1 peptide expressed in UTX-1K37; (B) On the second doublet, the polyclonal UTY-1 antiserum only detects the corresponding parental UTY-1 peptide sequence cloned in the UTY- $1 \mathrm{~K} 36$ recombinant. First lane in A and last lane in B present the Western Froxx all-in-one protein ladder fragments highlighting the 20,30,50 kDa marker fragments. For further description, see 'Materials and methods' section and main text.

This work is licensed under a Creative Commons Attribution-NonCommercial-NoDerivatives 4.0 International License.
aded from Bioscientifica.com at 04/25/2023 11:52:58PM 

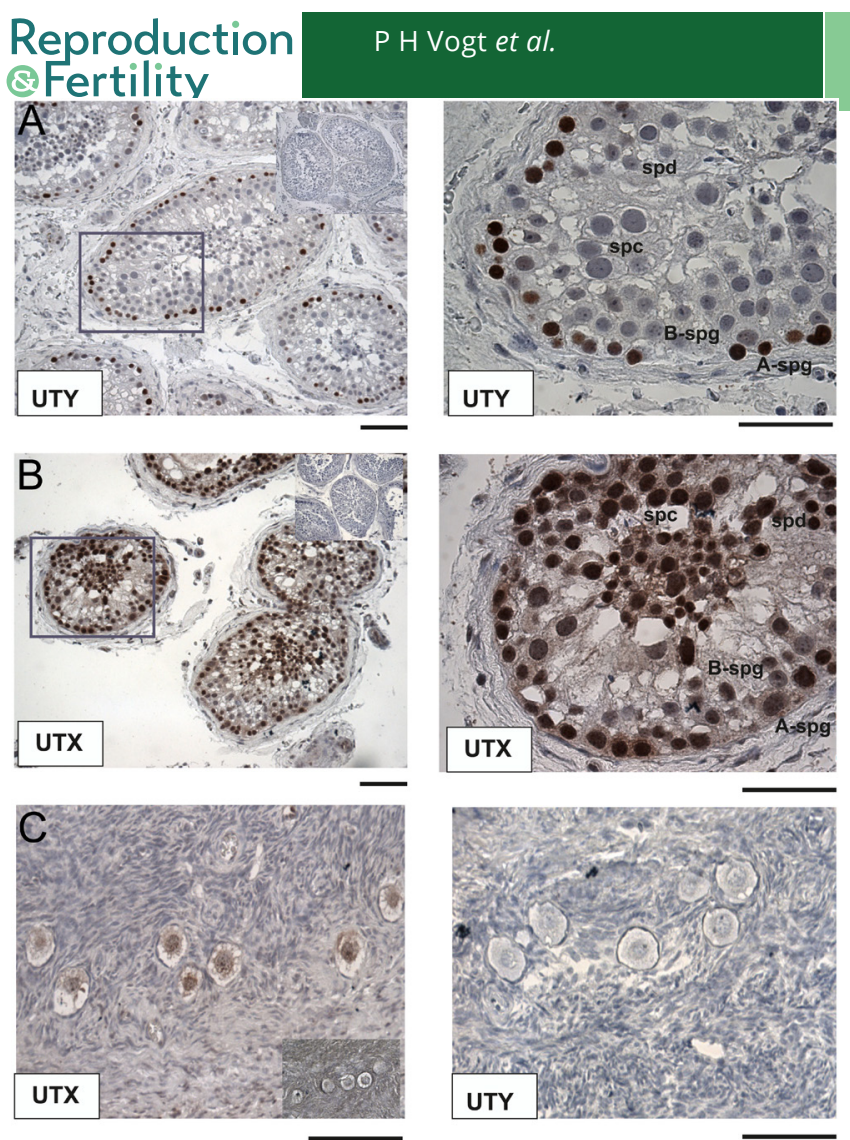

Figure $\mathbf{2}$ Immunohistochemical localisation of UTY and UTX protein expression in serial sections of human testes and ovarian tissue after staining with UTY-1 and UTX-1 polyclonal antisera, respectively. (A) UTY is expressed significantly only in A spermatogonia (A-spg) located at the basal membrane. See at the right section enlargement of the picture from the left marked with square (A-spg, A-spermatogonia; B-spg, B

spermatogonia; spc, spermatocytes; spd, spermatids). (B) UTX expression is more spread in pre-meiotic male germ cells, and in round spermatids. See section enlargement at the right of picture from the left marked with square (abbreviations used are described in A). No reaction was found in control tissue sections of the same samples incubated with UTY-1 and UTX-1 pre-immune rabbit sera, respectively (see inserts in pictures at the left in A and B, respectively). (C) In the ovarian tissue section, only UTX expression is visible in the primordial female germ cells as expected (on the left). Lack of UTY expression in serial sections of the same tissue (on the right) confirms the specificity of both antisera for only their parental proteins UTX and UTY, respectively. Insert on the left: UTX picture display incubation of the same ovarian tissue section with the pre-immune rabbit serum of UTX-1. No positive staining reaction can be documented. Scale bars: $50 \mu \mathrm{m}$.

UTX-1 antisera mark the expression of only human UTY or UTX proteins, respectively.

\section{UTY and UTX proteins are expressed in human germ cells}

We first now wanted to explore with these UTY-1 and UTX-1 polyclonal antisera, where UTY and UTX proteins are expressed in human male germ cells after puberty. Immunohistochemical experiments on serial tissue sections of human testes with normal spermatogenesis revealed expression of UTY in A spermatogonia located Published by Bioscientifica Ltd
UTY and UTX expression in

human spermatogonia predominantly at the basal membrane (Fig. 2A). UTX is expressed comparable in these pre-meiotic male germ cells. However, the associated UTX-1 staining pattern suggests that UTX expression is more spread in the distinct types of spermatogonia, and additionally expressed in spermatocytes and round spermatids (Fig. 2B). In order to confirm the specificity of the observed UTY and UTX germ cell expression, we also analysed the expression of both proteins in some ovarian tissue sections (Fig. 2C). We only found a significant staining pattern with the UTX-1 antiserum marking UTX expression in the primordial female germ cells of the follicles, but no UTY-1 staining pattern. This confirms that both antisera detect expression of only their parental UTX and UTY proteins, respectively.

\section{UTY and UTX are expressed during the development of foetal male germ cells}

Expression of AZFa candidate gene, UTY, in human spermatogonia after puberty displays a similar pattern to that described earlier for $D D X 3 Y$, the major AZFa gene (Ditton et al. 2004). This would confirm our basic assumption that UTY is part of AZFa functional for promoting the pre-meiotic male germ cells towards meiosis (Vogt et al. 2007). To collect further experimental, we also analysed the expression of UTY and UTX in immunohistochemical experiments with the polyclonal UTY-1 antiserum proven to detect only UTY proteins (Figs 1 and 2) also on fetal testis tissue sections and compare its staining pattern with that of UTX-1 antiserum.

UTY expression was first found in fetal germ cells at the 16th gestation week (gw) (Fig. 3A). No UTY expression was found in fetal germ cells at the 15th gestation week. At 16 th gw the fetal gonocytes are male determined and begin maturing asynchronously towards pre-spermatogonia also called T1 spermatogonia (Gueler et al. 2012). UTX expression seems to be lower than that of UTY at this foetal germ cell phase; its staining pattern is difficult to distinguish from that of the pre-immune-serum analysed in parallel. However, some weeks later UTY and UTX expression looks comparable (Fig. 3B: 25 gw; 3C: 33 gw). At the 41 gestation week, we could observe only UTY expression, whereas staining with UTX-1 displays only some intercellular background staining also observed with the pre-immune-serum (Fig. 3D).

We can conclude that the pattern of UTY expression in human foetal male germ cells is comparable to that of DDX3Y described earlier (Gueler et al. 2012). Both encoded proteins are expressed predominantly in spermatogonia; their loss should therefore interfere with the pre-meiotic

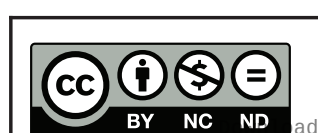

This work is licensed under a Creative Commons Attribution-NonCommercial-NoDerivatives 4.0 International License. ded from Bioscientifica.com at 04/25/2023 11:52:58PM 

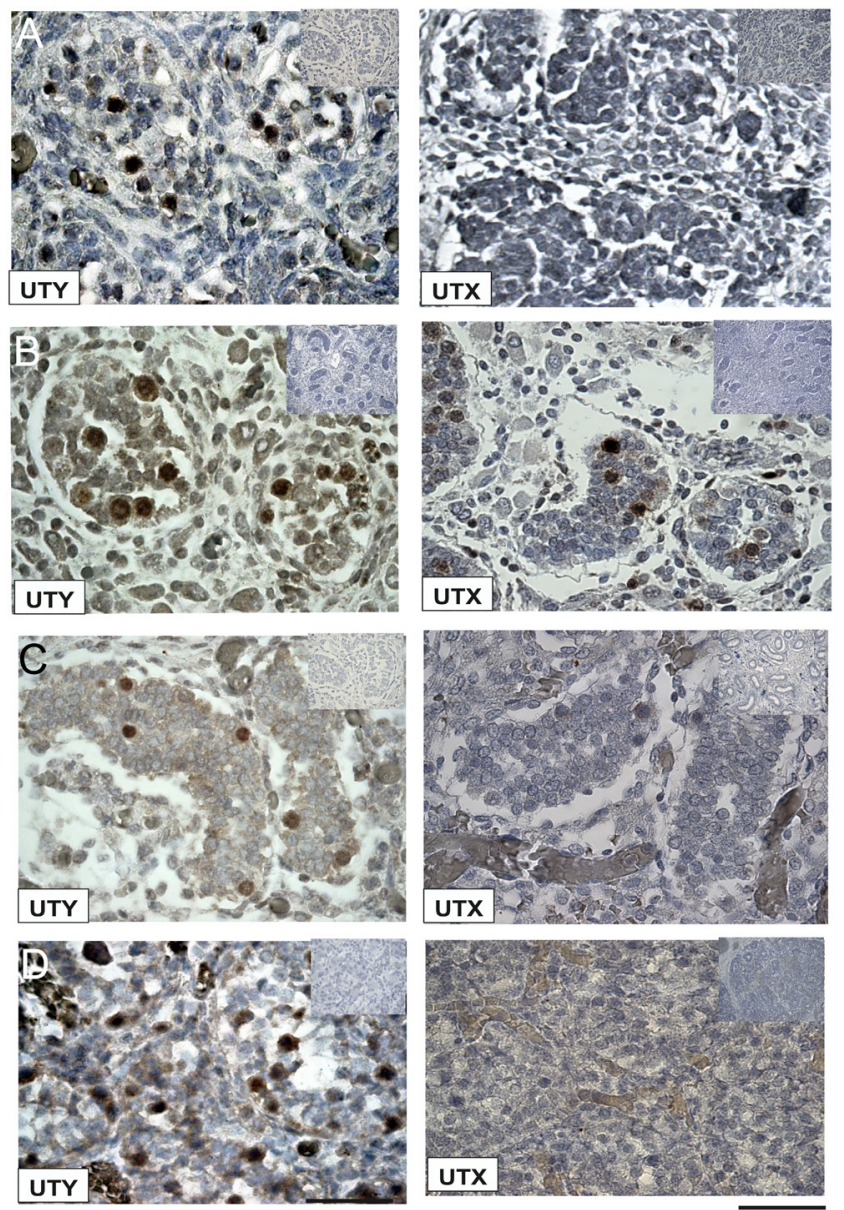

Figure $\mathbf{3} \mathrm{Immunohistochemical} \mathrm{staining} \mathrm{with} \mathrm{UTY-1} \mathrm{and} \mathrm{UTX-1} \mathrm{antisera}$ for comparative analysis of UTY and UTX protein expression during fetal male germ cells development. (A) UTY and UTX staining pattern in fetal germ cells at 16th gestation week (gw) display stronger UTY expression in these gonocytes. Some weeks later (B: $25 \mathrm{gw}$; C: $33 \mathrm{gw}$ ) UTY and UTX expression looks comparable. (D) At 41 gestation week only UTY expression could be observed, whereas UTX expression is significantly reduced and becomes comparable to the background level (see also pre-immune staining pattern at this germ cell phase: insert at the right). Control tissue sections incubated with the UTY-1 and the UTX-1 pre-immune rabbit serum (see inserts at the right in each picture) display no specific staining patterns. Scale bar length for $50 \mu \mathrm{m}$ shown on the right at $D$ is the same in each picture displayed here.

human male germ cell development. The UTY gene is, therefore, most likely another functional part of AZFa as suggested earlier (Wimmer et al. 2002).

\section{Comparison of UTY and DDX3Y expression in germ cell nests of females with complete gonadal dysgenesis (CGD) presenting gonadoblastoma or dysgerminoma pathology}

AZFa gene, DDX3Y, was found recently to be part of the Gonadoblastoma susceptibility Y (GBY) locus overlapping with AZFa in proximal Yq11 (Vogt et al. 2019). We, therefore, wanted to know whether GBY also includes the UTY gene. For this purpose, we compare the staining pattern of UTY-1 (marking expression of only UTY, see above) with that of DBY-10 (marking expression of only DDX3Y proteins; see Ditton et al. 2004) in serial gonadal tissue sections of two DSD-XY individuals with complete gonadal dysgenesis (CGD: Swyer syndrome). One sample (GBX88) presents in some of the undifferentiated gonadal tissue regions local germ cell nests with Gonadoblastoma (GB) pathology. One sample (GBY121) was found with dysgerminoma cells spreading in the undifferentiated gonadal tissue regions. GB cells are pre-malignant precursor cells developing towards germ cell tumour cells. These are designated as dysgerminoma when surrounded by granulosa cells marked by FOXL2 expression (BuellGutbrod et al. 2011).

We found comparable staining patterns with DBY-10 and UTY-1, marking comparable expression of DDX3Y and UTY in the gonadoblastoma cells of GBY88 in all tissue sections analysed (Fig. 4A). A similar strong expression of both proteins was also found in the dysgerminoma cells of GBY121 (Fig. 4B). We can thus conclude that the GBY tumour susceptibility locus on the long arm of the human Y chromosome, as presented in more detail earlier (Vogt et al. 2019), most likely includes also the UTY gene.
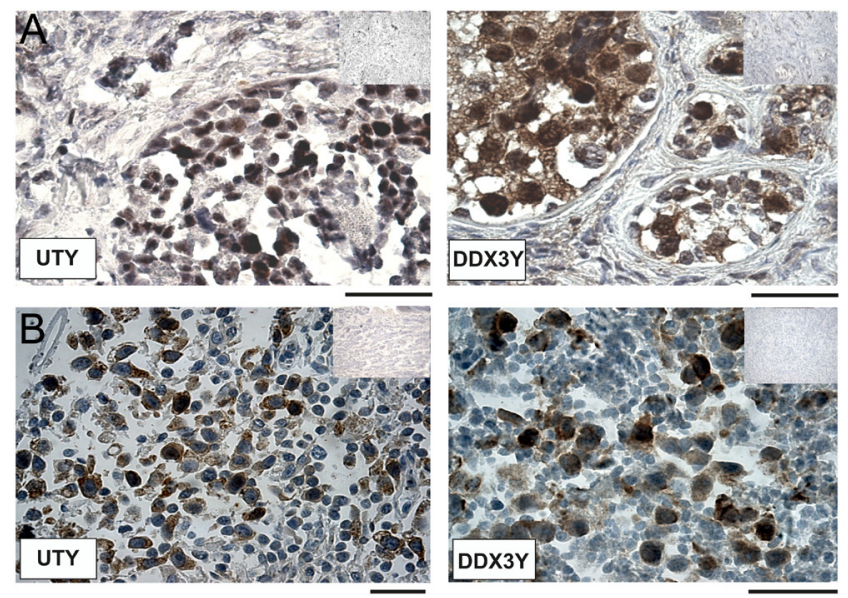

Figure 4 Immunohistochemical staining pattern with UTY-1, respectively, DBY-10 marks UTY, respectively, DDX3Y expression on serial tissues sections of two DSD-XY individuals with Swyer syndrome during tumour development. (A) GBY88 patient (16 years age) has developed premalignant gonadoblastoma cells in local germ cell nests of the undifferentiated gonadal tissue regions. Strong UTY and DDX3Y expression mark the gonadoblastoma pathology as described earlier (Vogt et al. 2019). (B) GBY121 patient (29 years age) has already developed dysgerminoma tumour cells from the pre-malignant gonadoblastoma cells. Again UTY and DDX3Y expression is comparable. It suggests that the genetic complexity of GBY tumour susceptibility locus in proximal Yq11 also includes the UTY gene. Scale bars: $50 \mu \mathrm{m}$.

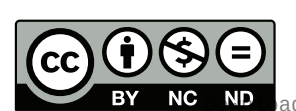

This work is licensed under a Creative Commons Attribution-NonCommercial-NoDerivatives 4.0 International License. 


\section{Discussion}

\section{UTY and UTX is functioning in human male germ cells}

Expression of UTY and UTX in human spermatogonia suggest that both histone 3 demethylase enzymes are involved in the H3K27 methylation/demethylation mediated chromatin modulation process observed during spermatogonia proliferation and differentiation from the spermatogonial stem cells (Tseng et al. 2015). Restriction of UTY expression in human A spermatogonia located at the basal membrane suggests that UTY supports UTX function also expressed in these cells probably including also the spermatogonia stem cell (SSC) fraction (Izadyar et al. 2011).

Other histone lysine methylases (KTMs) and -demethylases (KDMs) are reported to be involved later during male germ cell development; namely in monitoring the pre-meiotic chromosome pairing processes by silencing unpaired chromosomes, respectively, in controlling the activation of some specific spermatid genes (Nottke et al. 2009). Thereby LSD1/KDM1 and JARID1/KDM5 act on demethylation of $\mathrm{H} 3 \mathrm{~K} 4 \mathrm{me} 2 / 1$, respectively, on H3K4me3/2 at zygotene/pachytene stage (Godmann et al. 2007) and JHDM2A/KDM3A mediates the demethylation of $\mathrm{H} 3 \mathrm{~K} 9 \mathrm{me} 2$ in late pachytene and round spermatids (Okada et al. 2007).

In the mouse germ line, it has been shown that Uty is required to support the function of its paralog Utx located in the chromatin domains of primordial germ cells (PGC). Utx expression activates genes in these precursor germ cells by H3K27me2/3 demethylation to support their further differentiation programme (Mansour et al. 2012). In mouse somatic cells, the Uty gene encodes a male--specific $\mathrm{H}-\mathrm{Y}$ epitope $\left(\mathrm{H}-\mathrm{YD}^{\mathrm{b}}\right)$ of the H-Y antigen locus expressed during early embryogenesis (Greenfield et al. 1996). Accordingly, in human somatic cells, UTY also expresses a specific $\mathrm{H}-\mathrm{Y}$ antigen (Warren et al. 2000). It has therefore been argued that UTY proteins are probably only required for some male cell specific functions being restricted to malespecific organs, such as the prostate (Dutta et al. 2016). However, UTY deletions seem not be associated with somatic pathologies although the genes transcripts and proteins were found to be expressed in multiple human tissues and in leukocytes (Lahn \& Page 1997; www.uniprot. org/uniprot/O14607).

In human, the cellular level of UTY and UTX expression indicates some gender-specific dosage control function (Bellott et al. 2014), and it has been shown that the dosage of their expression is dependent on the genes copy number (Raznahan et al. 2018). Increased levels of
UTY expression are associated with a 50\% increased risk to suffer from a coronary artery disease, especially when the $\mathrm{Y}$ chromosome of these men is from Y haplogroup 'I' (Bloomer et al. 2013). Accordingly, there should be a cellular balanced UTX and UTY expression profile that can compensate each other. However, UTY is reported to have only a low enzymatic histone 3 K27 demethylase activity compared to UTX (Walport et al. 2014). Consequently, the efficiency of the UTY histone demethylase function is lower than that of the UTX protein and UTY expression is not as effective as UTX expression to suppress tumour development (van Haaften et al. 2009).

A major question would then be whether UTY and then probably also the UTX protein are only functional as H3K27me3 demethylase enzymes in the pre-meiotic male germ cells, respectively, whether both proteins rather serve for a histone demethylase independent function to control distinct germ cell genes required in human spermatogonia for balancing the spermatogonia proliferation and differentiation rates from the SSC pool after puberty.

The histone demethylase independent function of UTX and UTY is probably based on their conserved N-terminal tetratricopeptide repeats (TPRs), which is not present in the third KDM6 protein member, JMJD3 (Walport et al. 2014). These TPR motifs are strongly conserved from yeast to human as functional important protein interaction motifs (D'Andrea \& Regan 2003). Accordingly, it has been shown that both paralogues do have similar functional roles in human metabolism and during development independent from their histone demethylase activity and these might even be co-regulated. Indeed, in mouse, both genes displayed a common pattern of transcription factors binding to the Utx and Uty promoters (Gazova et al. 2019).

It is, therefore, most likely, that UTY and probably then also UTX also express some demethylase independent function(s) in human pre-meiotic male germ cells after puberty.

During foetal male germ cell development, we observed UTY and UTX expression visible starting around the $16^{\text {th }}$ gestation week (Fig. 3A). No staining pattern with UTY-1 and UTX-1 antibodies could be observed on foetal gonads tissue sections of the 15th gestation week (data not shown). Interestingly, whereas UTY expression was found consistently along foetal germ cell development, UTX expression looks variable and comparable to UTY only at the 25th gestation week (Fig. 3B). Significant lower UTX expression was found at the 16th and 33th gestation week; the UTX-1 staining pattern became rather visible in our immunohistochemical experiments although performed https://raf.bioscientifica.com

https://doi.org/10.1530/RAF-20-0049 (c) 2021 The authors Published by Bioscientifica Ltd
This work is licensed under a Creative Commons Attribution-NonCommercial-NoDerivatives 4.0 International License. International License.
ded from Bioscientifica.com at 04/25/2023 11:52:58PM 
in parallel with the specific UTY-1 and UTX-1 antisera in serial sections of the same foetal gonad specimens (Fig. 3A and C). No UTX expression could be detected at the 41st gestation week (Fig. 3D).

Stronger than UTX and consistent UTY expression in foetal spermatogonia would support our assumption of the functional importance of this $Y$ gene together with the neighboured DDX $3 Y$ gene just for foetal male germ line development during their proliferation phase (Gueler et al. 2012). This also would fit to our observation that during adult spermatogonia development, UTY expression is concentrated in the proliferating A spermatogonia fraction located at the basal membrane (Fig. 2A).

\section{Human UTY is part of AZFa locus on human Y chromosome}

The genomic neighbourhood of $U T Y$ and DDX3Y genes on the human $\mathrm{Y}$ chromosome is conserved on the $\mathrm{Y}$ chromosome of distinct mammalian lineages including rodents and primates (Murphy et al. 1999, Wimmer et al. 2002, Li et al. 2013). This has suggested a conserved function of both proteins in the male germ line of these mammals. Accordingly, it has been designated as 'AZFa locus' (Wimmer et al. 2002, Vogt et al. 2007).

In this paper, we present strong experimental evidence that the proposed AZFa candidate gene, UTY, is involved in the control of the proliferation and differentiation process of foetal and adult spermatogonia, like the major AZFa gene, $D D X 3 Y$; both are predominantly expressed in spermatogonia located at the basal membrane (for DDX3Y see: Ditton et al. 2004, Gueler et al. 2012, Ramathal et al. 2015). Accordingly, DDX3Y deletions are reported to cause a severe pathology in the male germ line leading eventually to complete absence of all pre-meiotic germ cells (Foresta et al. 2000, Vogt et al. 2017). However, in some cases, patients with complete AZFa deletions, including the DDX3Y - but not the UTY gene - still display some spermatogonia in their testis tubules, suggesting that the complete germ cell aplasia observed in most AZFa patients may be probably only a secondary and age-dependent consequence of the primary mutation defect, namely, reduction of the spermatogonia proliferation rate (for further discussion see also Vogt et al. 2017, 2008). Most interestingly, like somatic UTY deletions, also DDX3Y deletions do not cause any somatic pathology in these infertile men, suggesting that DDX3Y like UTY function is restricted to the male germ line.

In one patient with complete absence of all germ cells in his testis tubules, we found a distal extension of the classical AZFa deletion interval, including additionally the UTY gene (Vogt et al. submitted). Not any spermatogonia were found in the patient testis tubules, presenting a complete Sertoli-Cell-Only (SCO) syndrome. Based on the germ cell UTY expression pattern presented in this paper (Figs 2 and 3), we may therefore speculate that infertile men with deletion of both these $\mathrm{Y}$ genes in AZFa, DDX $3 Y$ and $U T Y$, indeed strengthens the primary testicular phenotype of the 'AZFa deletion' pathology, that is, disruption of spermatogonia proliferation cycle. DDX3Y expression is known to be functional during the G1-S phase of the cell cycle (Ditton et al. 2004, Ramathal et al. 2015).

However, to be cautious: until we have not found also some single $U T Y$ deletion/point mutations on the $\mathrm{Y}$ chromosome of infertile men with SCO, it is not yet proven, whether there is also some functional link between UTY and DDX3Y expression in the same pre-meiotic human male germ cells.

\section{UTY is part of the GBY susceptibility locus in proximal Yq11}

We have recently shown that $D D X 3 Y$ and TSPY- is part of the Gonadoblastoma Locus of the human Y chromosome (GBY) expressed in the aberrant male germ cells of women with some disorders of sexual development (DSD) and a Y chromosome in their karyotype (DSD-XY individuals; Vogt et al. 2019). In this paper, we now present experimental evidence that UTY probably also contribute to this GBY tumour susceptibility function. In this paper, we analysed UTY expression in the aberrant male germ cells of the dysgenetic gonads of two DSD-XY individuals with complete gonadal dysgenesis (Swyer syndrome) when developing gonadoblastoma, respectively, dysgerminoma cells (Fig. 4). UTY expression was found to be comparable to that of DDX3Y in the dysgenetic gonads of both patients, which do have still some germ cell nests in their streak gonads. The molecular origin for their high risk to develop gonadoblastoma and further dysgerminoma is generally based on their phenotype of pluripotency marked by OCT3/4 expression (Cheng et al. 2007; for further details, see Cools et al. 2009, Vogt et al. 2019). Our data confirm the basic assumption discussed earlier that probably all AZFa Y genes functional for the pre-meiotic proliferationdifferentiation balance of spermatogonia during male germ cell development support tumour development in dysgenetic female gonads because of some dysregulation in their aberrant germ cells. 
Declaration of interest

There is no conflict of interest that could be perceived as prejudicing the impartiality of the research reported.

\section{Funding}

This study was funded by grant Vo403/16/1-2 of the Deutsche Forschungsgemeinschaft (DFG) to PHV and by a clinical grant to T.S.

\section{Author contribution statement}

PHV conceived the study and wrote the paper. JZ and UB performed the experiments and analysed the data. TS take care of the basic clinical support, especially with providing tissue samples of DSD-XY patients and support preparing the final draft of this paper.

\section{Acknowledgements}

The authors thank all co-workers in the lab and in the outpatient clinic not included on the co-author list, especially Petra Frank-Herrmann and Peter Sinn, for their most valuable support in evaluating the clinical human tissue samples of the CGD patients. Ewa Rijpert-De Meyts and coworkers, Department of Pathology, Rigshospitalet, Copenhagen University, is thanked for providing us with the human foetal testis tissue samples. Rainer Büttner, Head of the Institute of Pathology, University Clinic Bonn, is thanked for the gonadal tissue sections with dysgerminoma pathology, which we contained in accordance with the ethical regulations of his local tissue bank. We also thank the National Centre for Tumour development (NCT; Heidelberg, Germany) for providing us with further gonadal tissue sections of both CGD patients in accordance with the regulations of the tissue bank and the approval of the ethics committee of Heidelberg University.

\section{References}

Accari SL \& Fisher PR 2015 Emerging roles of JmjC domain-containing proteins. International Review of Cell and Molecular Biology 319 165-220. (https://doi.org/10.1016/bs.ircmb.2015.07.003)

Banka S, Lederer D, Benoit V, Jenkins E, Howard E, Bunstone S, Kerr B, McKee S, Lloyd IC, Shears D et al. 2015 Novel KDM6A (UTX) mutations and a clinical and molecular review of the X-linked Kabuki syndrome (KS2). Clinical Genetics 87 252-258. (https://doi. org/10.1111/cge.12363)

Bellott DW, Hughes JF, Skaletsky H, Brown LG, Pyntikova T, Cho TJ, Koutseva N, Zaghlul S, Graves T, Rock S et al. 2014 Mammalian Y chromosomes retain widely expressed dosage-sensitive regulators. Nature 508 494-499. (https://doi.org/10.1038/nature13206)

Bloomer LDS, Nelson CP, Eales J, Denniff M, Christofidou P, Debiec R, Moore J, Cardiogenics Consortium, ZukowskaSzczechowska E, Goodall AH et al. 2013 Male-Specific Region of the Y Chromosome and Cardiovascular Risk. Phylogenetic Analysis and Gene Expression Studies. Arteriosclerosis, Thrombosis, and Vascular Biology 33 1722-1727. (https://doi.org/10.1161/ATVBAHA.113.301608)

Buell-Gutbrod R, Ivanovic M, Montag A, Lengyel E, Fadare 0 \& Gwin K 2011 FOXL2 and SOX9 distinguish the lineage of the sex cord-stromal cells in gonadoblastomas. Pediatric and Developmental Pathology 14 391-395. (https://doi.org/10.2350/10-12-0943-OA.1)
Cheng L, Sung MT, Cossu-Rocca P, Jones TD, MacLennan GT, De Jong J, Lopez-Beltran A, Montironi R \& Looijenga LH 2007 OCT4: biological functions and clinical applications as a marker of germ cell neoplasia. Journal of Pathology 211 1-9. (https://doi. org/10.1002/path.2105)

Cools M, Looijenga LH, Wolffenbuttel KP \& Drop SL 2009 Disorders of sex development: update on the genetic background, terminology and risk for the development of germ cell tumours. World Journal of Pediatrics 5 93-102. (https://doi.org/10.1007/s12519-009-0020-7)

D`Andrea LD \& Regan L 2003 TPR proteins: the versatile helix. Trends in Biochemical Sciences 28 655-662. (https://doi.org/10.1016/j. tibs.2003.10.007)

Ditton HJ, Zimmer J, Kamp C, Rajpert-De Meyts E \& Vogt PH 2004 The $A Z F a$ gene $D B Y(D D X 3 Y)$ is widely transcribed but the protein is limited to the male germ cells by translation control. Human Molecular Genetics 13 2333-2341. (https://doi.org/10.1093/hmg/ddh240)

Dutta A, Le Magnen C, Ouyang X, Califano A \& Abate-Shen C 2016 Identification of an NKX3.1-G9a-UTY transcriptional regulatory networkthat controls prostate differentiation. Science 352 1576-1580.

Faundes V, Newman WG, Bernardini L, Canham N, ClaytonSmith J, Dallapiccola B, Davies SJ, Demos MK, Goldman A, Gill H et al. 2018 Histone lysine methylases and demethylases in the landscape of human developmental disordes. American Journal of Human Genetics 102 175-187. (https://doi.org/10.1016/j. ajhg.2017.11.013)

Foresta C, Ferlin A \& Moro E 2000 Deletion and expression analysis of AZFa genes on the human Y chromosome revealed a major role for Dby in male infertility. Human Molecular Genetics 9 1161-1169. (https:// doi.org/10.1093/hmg/9.8.1161)

Gazova I, Lengeling A \& Summers KM 2019 Lysine demethylases KDM6A and UTY; the X and Y of histone demethylation. Molecular Genetics and Metabolism 127 31-44. (https://doi.org/10.1016/j.ymgme.2019.04.012)

Godmann M, Auger V, Ferraroni-Aguar V, Di Sauro A, Sette C, Behr R \& Kimmins S 2007 Dynamic regulation of histone 3 methylation at lysine 4 in mammalian spermatogenesis. Biology of Reproduction 77 754-764. (https://doi.org/10.1095/biolreprod.107.062265)

Greenfield A, Scott D, Pennisi D, Ehrmann I, Ellis P, Cooper L,

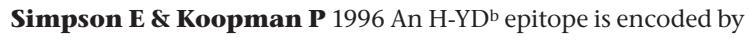
a novel mouse Y chromosome gene. Nature Genetics 14 474-478. (https://doi.org/10.1038/ng1296-474)

Gueler B, Sonne SB, Zimmer J, Hilscher B, Hilscher W, Græm N, Rajpert-De Meyts E \& Vogt PH 2012 AZFa protein DDX3Y is differentially expressed in human male germ cells during development and in testicular tumours: new evidence for phenotypic plasticity of germ cells. Human Reproduction 27 1547-1555. (https://doi. org/10.1093/humrep/des047)

Iwamori N, Iwamori T \& Matzuk MM 2013 H3K27 demethylase, JMJD3, regulates fragmentation of spermatogonial cysts. PLoS ONE $\mathbf{8}$ e72689. (https://doi.org/10.1371/journal.pone.0072689)

Izadyar F, Wong J, Maki C, Pacchiarotti J, Ramos T, Howerton K, Yuen C, Greilach S, Zhao HH, Chow M et al. 2011 Identification and characterization of repopulating spermatogonial stem cells from the adult human testis. Human Reproduction 26 1296-1306. (https:// doi.org/10.1093/humrep/der026)

Kamp C, Huellen K, Fernandes S, Sousa M, Schlegel PN, Mielnik A, Kleiman S, Yavetz H, Krause W, Kupker W et al. 2001 High deletion frequency of the complete AZFa sequence in men with Sertoli-cell-only syndrome. Molecular Human Reproduction 7 987-994. (https://doi.org/10.1093/molehr/7.10.987)

Lahn BT \& Page DC 1997 Functional coherennce of the human Y chromosome. Science 278 675-680. (https://doi.org/10.1126/ science.278.5338.675)

Lee MG, Villa R, Trojer P, Norman J, Yan KP, Reinberg D, Di Croce L \& Shiekhattar R 2007 Demethylation of H3K27 regulates Polycomb recruitment and H2A ubiquitination. Science 318 447-450. (https://doi.org/10.1126/science.1149042)

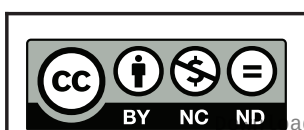

This work is licensed under a Creative Commons Attribution-NonCommercial-NoDerivatives 4.0 International License. ded from Bioscientifica.com at 04/25/2023 11:52:58PM 
Li G, Davis BW \& Raudsepp T 2013 Comparative analysis of mammalian Y chromosome illuminates ancestral structure and lineage-specific evolution. Genome Research 23 1486-1495. (https://doi. org/10.1101/gr.154286.112)

Luddi A, Margollicci M, Gambera L, Serafini F, Cioni M, De Leo V, Balestri P \& Piomboni P 2009 Spermatogenesis in a man with complete deletion of USP9Y . New England Journal of Medicine 360 881-885. (https://doi.org/10.1056/NEJMoa0806218)

Mansour AA, Gafni O, Weinberger L, Zviran A, Ayyash M, Rais Y, Krupalnik V, Zerbib M, Amann-Zalcenstein D, Maza I et al. 2012 The H3K27 demethylase Utx regulates somatic and germ cell epigenetic reproghramming. Nature $\mathbf{4 8 8}$ 409-413. (https://doi. org/10.1038/nature11272)

Mu W, Starmer J, Shibata Y, Yee D \& Magnuson T 2017 EZH1 in germ cells safeguards the function of PRC2 during spermatogenesis. Developmental Biology 424 198-207. (https://doi.org/10.1016/j. ydbio.2017.02.017)

Murphy WJ, Sun S, Chen ZQ, Pecon-Slattery J \& O'Brienet S J 1999 Extensive Conservation of sex chromosome organization between cat and human revealed by parallel radiation hybrid mapping. Genome Research 9 1223-1230. (https://doi.org/10.1101/gr.9.12.1223)

Nottke A, Colaiacovo MP \& Shi Y 2009 Developmental roles of the histone lysine demethylases. Development 136 879-889. (https://doi. org/10.1242/dev.020966)

Okada Y, Scott G, Ray MK, Misina Y \& Zhang Y 2007 Histone demethylase JHDM2A is critical for Tnp1 and Prm1 transcription and spermatogenesis. Nature 450 119-123. (https://doi.org/10.1038/ nature06236)

Pasini D, Bracken AP, Agger K, Christensen J, Hansen K, Cloos PA \& Helin K 2008 Regulation of stem cell differentiation by histone methyltransferases and demethylases. Cold Spring Harbor Symposia on Quantitative Biology 73 253-263. (https://doi.org/10.1101/ sqb.2008.73.009)

Ramathal C, Angulo B, Sukhwani M, Cui J, Durruthy-Durruthy J, Fang F, Schanes P, Turek PJ, Orwig KE \& Reijo Pera R 2015 DDX3Y gene rescue of a Y chromosome AZFa deletion restores germ cell formation and transcriptional programs. Scientific Reports 515041 (https://doi.org/10.1038/srep15041)

Raznahan A, Parikshak NN, Chandran V, Blumenthal JD, Clasen LS, Alexander-Bloch AF, Zinn AR, Wangsa D, Wise J, Murphy DGM et al. 2018 Sex chromosome dosage effects on gene expression in humans. PNAS 115 7398-7403. (https://doi.org/10.1073/ pnas.1802889115)

Robinson G, Parker M, Kranenburg TA, Lu C, Chen X, Ding L, Phoenix TN, Hedlund E, Wei L, Zhu X et al. 2012 Novel mutations target distinct subgroups of medulloblastoma. Nature $\mathbf{4 8 8}$ 43-48. (https://doi.org/10.1038/nature11213)

Tiepolo L \& Zuffardi 01976 Localization of factors controlling spermatogenesis in the nonfluorescent portion of the human $\mathrm{Y}$ chromosome long arm. Human Genetics 34 119-124. (https://doi. org/10.1007/BF00278879)

Tseng YT, Liao HF, Yu CY, Mo CF \& Lin SP 2015 Epigenetic factors in the refgulation of prospermatogonia and spermatogonial stem cells. Reproduction 150 R77-R91. (https://doi.org/10.1530/REP-14-0679)

Tyler-Smith C \& Krausz C 2009 The will-o'-the-wisp of genetics-hunting for the azoospermia factor gene. New England Journal of Medicine 360 925-927. (https://doi.org/10.1056/NEJMe0900301)
Ulbright TM \& Young RH 2014 Gonadoblastoma an selected other aspects of gonadal pathology in young patients with disorders of sex development. Seminars in Diagnostic Pathology 31 427-440. (https:// doi.org/10.1053/j.semdp.2014.07.001)

van Haaften G, Dalgliesh GL, Davies H, Chen L, Bignell G, Greenman C, Edkins S, Hardy C, O'Meara S, Teague J et al. 2009 Somatic mutations of the histone H3K27 demethylase, UTX, in human cancer. Nature Genetics 41 521-523. (https://doi.org/10.1038/ ng.349)

Vogt PH, Edelmann A, Kirsch S, Henegariu O, Hirschmann P, Kiesewetter F, Köhn FM, Schill WB, Farah S, Ramos C et al. 1996 Human Y chromosome azoospermia factors (AZF) mapped to different subregions in Yq11. Human Molecular Genetics 5 933-943 (https://doi.org/10.1093/hmg/5.7.933)

Vogt PH, Ditton HJ, Kamp C \& Zimmer J 2007 Structure and function of AZFa locus in human spermatogenesis. In The Y Chromosome and Male Germ Cell Biology in Health and Diseases. New Jersey, USA, pp.91-125. YFC Lau \& WY Chan Eds.: Press: World Scientific.

, Vogt PH Falcao CL, Hanstein R. \& Zimmer J 2008 The AZF proteins. International Journal of Andrology 31 383-394. (https://doi.org/10.1111/ j.1365-2605.2008.00890.x)

Vogt PH, Bender U, Zimmer J \& Strowitzki T 2017 Human Y chromosome and male infertility: forward and back from azoospermia factor chromatin structure to azoospermia factor gene function. In Monographs in Human Genetics, 21 57-73. PH Vogt, Ed.:Basel: Karger. (https://doi.org/10.1159/000477278)

Vogt PH, Besikoglu B, Bettendorf M, Frank-Herrmann P, Zimmer J, Bender U, Knauer-Fischer S, Choukair D, Sinn P, Lau Y-FC et al. 2019 Gonadoblastoma Y locus genes expressed in germ cells of individuals with dysgenetic gonads and a Y chromosome in their karyotypes include DDX3Y and TSPY. Human Reproduction 34 770-779. (https://doi.org/10.1093/humrep/dez004)

Walport LJ, Hopkinson RJ, Vollmar M, Madden SK, Gileadi C, Oppermann U, Schofield CJ \& Johansson C 2014 Human UTY(KDM6C) is a male-specific Ne-methyl lysyl demethylase. Journal of Biological Chemistry 289 18302-18313. (https://doi.org/10.1074/jbc. M114.555052)

Warren EHW, Gavin MA, Simpson E, Chandler P, Page DC, Disteche C, Stankey KA, Greenberg PD \& Riddell SR 2000 The human UTY gene encodes a novel HLA-B8 restricted H-Y- antigen. Journal of Immunology 164 2807-2814. (https://doi.org/10.4049/ jimmunol.164.5.2807)

Welstead GG, Creyghton MP, Bilodeau S, Cheng AW, Markoulaki S, Young RA \& Jaenisch R 2012 X-linked H3K27me3 demethylase Utx is required for embryonic development in a sexspecific manner. PNAS 109 13004-13009. (https://doi.org/10.1073/ pnas.1210787109)

Wimmer R, Kirsch S, Weber A, Rappold GA \& Schempp W 2002 The azoospermia region AZFa: a evolutionary view. Cytogenetic and Genome Research 99 146-150. (https://doi.org/10.1159/000071586)

Received in final form 23 April 2021

Accepted 11 May 2021

Accepted Manuscript published online 11 May 2021 https://raf.bioscientifica.com

https://doi.org/10.1530/RAF-20-0049 (c) 2021 The authors Published by Bioscientifica Ltd
This work is licensed under a Creative Commons Attribution-NonCommercial-NoDerivatives 4.0 International License. ded from Bioscientifica.com at 04/25/2023 11:52:58PM 